\title{
Acute Leukemia in Association With Langerhans Cell Histiocytosis
}

\author{
R. Maarten Egeler, MD, PhD, Joseph P. Neglia, MD, MPH, Maurizio Aricò, MD, \\ Blaise E. Favara, MD, Andreas Heitger, MD, and Mark E. Nesbit, MD
}

\begin{abstract}
Langerhans cell histiocytosis ( $\mathrm{LCH}$ ) and malignancy occurring in the same individual is unusual and has generally been the subject of isolated case reports. To better define the occurrence of these events a registry of cases with synchronous or asynchronous $\mathrm{LCH}$ and malignancy was developed with the cooperation of the Histiocyte Society.

In 1991 the Histiocyte Society surveyed its members requesting information on cases in which LCH was associated with malignancy. The questionnaire was mailed to all members of the society and specifically requested information on the clinical and laboratory features of the cases, disease evolution, and response to therapy. Retrospective reporting was allowed. With this initial data, an ongoing registry of $\mathrm{LCH}$ patients with associated malignancy was begun of such cases, including evolution and response to therapy.

Twenty-seven patients were enrolled during the first year of the registry, of whom 4 patients had the association of LCH with a malignant lymphoma and 10 cases had an association of $\mathrm{LCH}$ with other types of solid tumor. The remaining 13 patients had the association of $\mathrm{LCH}$ with acute leukemia. In five cases, $\mathrm{LCH}$ was associated with acute lymphoblastic leukemia FAB L1 (ALL). In four cases the ALL preceded the LCH by 6 months to 1 year. In four of five patients the $\mathrm{LCH}$ was
\end{abstract}

localized; in two instances the $\mathrm{LCH}$ was treated with chemotherapy. In all cases the leukemia was treated according to local standard ALL protocols and in one case autologous bone marrow transplantation (ABMT) was performed at relapse. Three patients are free of leukemia, one of whom has persistent localized $\mathrm{LCH}$ of the skin. Two patients died of the ALL, one of whom was free of the $\mathrm{LCH}$ at the time of death. In eight instances $\mathrm{LCH}$ was reported in association with acute myeloid leukemia (AML). Six of these patients had a generalized form of $\mathrm{LCH}$. In seven the diagnosis of $\mathrm{LCH}$ preceded the diagnosis of leukemia by more than 2 years (median 4 years). In the remaining patient both diagnoses were made concurrently. In all seven cases in whom $\mathrm{LCH}$ was the initial diagnosis the treatment consisted of chemotherapy and/or radiotherapy. Seven patients died from the AML, five without evidence of $\mathrm{LCH}$.

The temporal patterns of the LCH-ALL and $\mathrm{LCH}$-AML associations are distinct with ALL usually preceding the diagnosis of $\mathrm{LCH}$ and AML succeeding it. Such a pattern is suggestive that in cases of ALL the LCH may be a reactive process while in cases of AML occurring after $\mathrm{LCH}$ the primary $\mathrm{LCH}$ therapy may play an inductive role in the leukemia. (c) 1994 Wiley-Liss, Inc.

Key words: Langerhans cell histiocytosis ( $\mathrm{LCH}$ ), acute leukemia, neoplasm, childhood

\section{INTRODUCTION}

A recent review has suggested that Langerhans cell histiocytosis ( $\mathrm{LCH})$ and malignant neoplasms may occur in the same individual in a frequency in excess of that expected by chance alone [1]. In this review, the most common associations seen were those of $\mathrm{LCH} /$ lymphoma and $\mathrm{LCH} /$ solid tumors, however $24 \%$ of the cases reported were of LCH occurring either before, after, or coincident with the diagnosis of acute leukemia. The occurrence of two unusual events in a single individual may provide an opportunity to better understand the etiology or pathogenesis of one or both disorders. To facilitate this an ongoing registry of patients in whom LCH and a malignancy occurred was initiated in 1991. The following report summarizes the first findings of the $\mathrm{LCH}-$ Malignancy Registry.

From Sophia Children's Hospital, Rotterdam, the Netherlands (R.M.E.); University of Minnesota School of Medicine, Minneapolis, Minnesota (J.P.N., M.E.N.); Università di Pavia, Pavia, Italy (M.A.); All Children's Hospital, St. Petersburg, Florida (B.E.F.); Center for Cancer and Transplantation Biology, Washington, DC (A.H.).

Received September 27, 1993; accepted November 26, 1993.

Address reprint requests to R. Maarten Egeler, M.D., Sophia Children's Hospital/University Hospital Dijkzigt, Erasmus University Rotterdam, Department of Pediatric Hematology-Oncology, Dr. Molewaterplein 60,3015 GJ Rotterdam, the Netherlands. 


\section{METHODS}

In October 1991 all members of the Histiocyte Society were mailed a questionnaire requesting them to submit data on any patient they were currently, or had previously encountered, with LCH and malignancy occurring in any temporal sequence. The questionnaire requested the clinical, pathological, and therapeutical data of such patients. Additionally, selected authors of manuscripts or abstracts describing these associations received the questionnaire requesting information. Retrospective reporting was allowed. Records from each case reported to the registry were reviewed to confirm the diagnosis of LCH by morphologic criteria of either a CDla positive phenotype and/or Birbeck granules evident on electron microscopy [2].

\section{RESULTS}

Between October 1991 and October 1992, 27 cases who were diagnosed with $\mathrm{LCH}$ in association with a malignancy were enrolled in the registry. Thirteen of the 27 cases had LCH associated with acute leukemia. Four cases had LCH and a malignant lymphoma and 10 cases had LCH and another type of solid tumor.

Among the 13 cases of $\mathrm{LCH} /$ leukemia, there were 5 cases of acute lymphoblastic leukemia (ALL) and 8 cases of $\mathrm{LCH}$ in association with acute myeloid leukemia (AML). Six cases (two ALL, four AML) were diagnosed at centers in North America. The remaining seven cases (three ALL, four AML) were enrolled from European centers.

\section{LCH and ALL}

In four of the five patients in this group the $\mathrm{LCH}$ was localized to either skin (1) or bone (3) only (Table I). The fifth case showed disseminated disease with involvement of lymph nodes, bone marrow, lungs, and liver. This patient and one with localized bone involvement were treated with chemotherapy. In the remaining patients with localized LCH "the therapy" consisted of a bone biopsy only (in the two localized bone cases) and electron beam irradiation (in the solitary skin involvement). In all but one instance the diagnosis of ALL preceded the diagnosis of LCH from by 6 to 12 months, with the LCH occurring while the patients were under active therapy. In the fifth patient the ALL developed 5.5 years after the $\mathrm{LCH}$ (in this case the LCH was treated with biopsy alone). The ALL in all five patients was classified as FAB L1 and only one patient showed cytogenetic abnormalities, a $9 p$ deletion. The age of the cases varied from 3.5 years to 9 years (median 6 years) at the time $\mathrm{LCH}$ was diagnosed.

The ALL was in all cases treated according to local standard protocols and one patient who relapsed under- went autologous bone marrow transplantation (ABMT). Three patients are in remission from their leukemia. One of these continues to have active, localized LCH of the skin. The remaining two patients died of ALL, of which one was free of the $\mathrm{LCH}$.

\section{LCH and AML}

Of the eight cases in which LCH was associated with AML, two patients had LCH localized to bone. The remaining six patients had a disseminated form of $\mathrm{LCH}$ with skin lesions in association with visceral organ involvement (4) and/or bone involvement (4) (Table I). All the cases with organ involvement showed organ dysfunction of bone marrow and/or liver and/or lungs.

The FAB classification of the AML did not show a specific pattern as M1, M4, and M5 were found in two cases each and M2 and M3 was established once. In one case the diagnoses of LCH and AML were made concurrently. In the remaining seven patients the diagnosis of $\mathrm{LCH}$ preceded the diagnosis of leukemia by more than 2 years (median 4 years). The age in this group varied from 3 months to 79 years, with a median of 7.5 years. In all the seven patients in whom $\mathrm{LCH}$ was the initial diagnosis the treatment consisted of chemotherapy and/or radiotherapy for 1-6 years (Table II). Cytogenetic abnormalities were found in four of the six cases studied. Only one patient remains alive, 7 months after ABMT. Of the seven patients who died from the AML, five did not show any sign of $\mathrm{LCH}$.

\section{DISCUSSION}

Twenty-seven cases of malignancy and LCH occurring in the same individual were reported to our registry during its initial year. In 13 of these, the associated malignancy was either ALL (five cases) or AML (eight cases). In reviewing these cases two distinct patterns of association appear evident; ALL preceding $\mathrm{LCH}$, and LCH preceding AML.

The association of $\mathrm{LCH}$ following a diagnosis of ALL (in four out of the five cases) suggests a reactive process, a pregenetic predisposition of ALL and $\mathrm{LCH}$, and/or a different clinical manifestation of the same disorder. As all of the cases were actively undergoing ALL therapy at the time of the LCH diagnosis it would seem plausible that the ALL therapy in some way played a role in the expression of the LCH. Since most children with ALL enter remission rapidly and show no evidence of leukemia during therapy, a reaction to the malignant process seems unlikely. Rather, it may be that there is a predisposition of patients with ALL to LCH, and that one or more of the treatments given to children with ALL act as a co-factor, possibly through immunosuppression. In the one case in which the diagnosis of LCH preceded that of ALL the LCH was localized to bone and was "treated" 


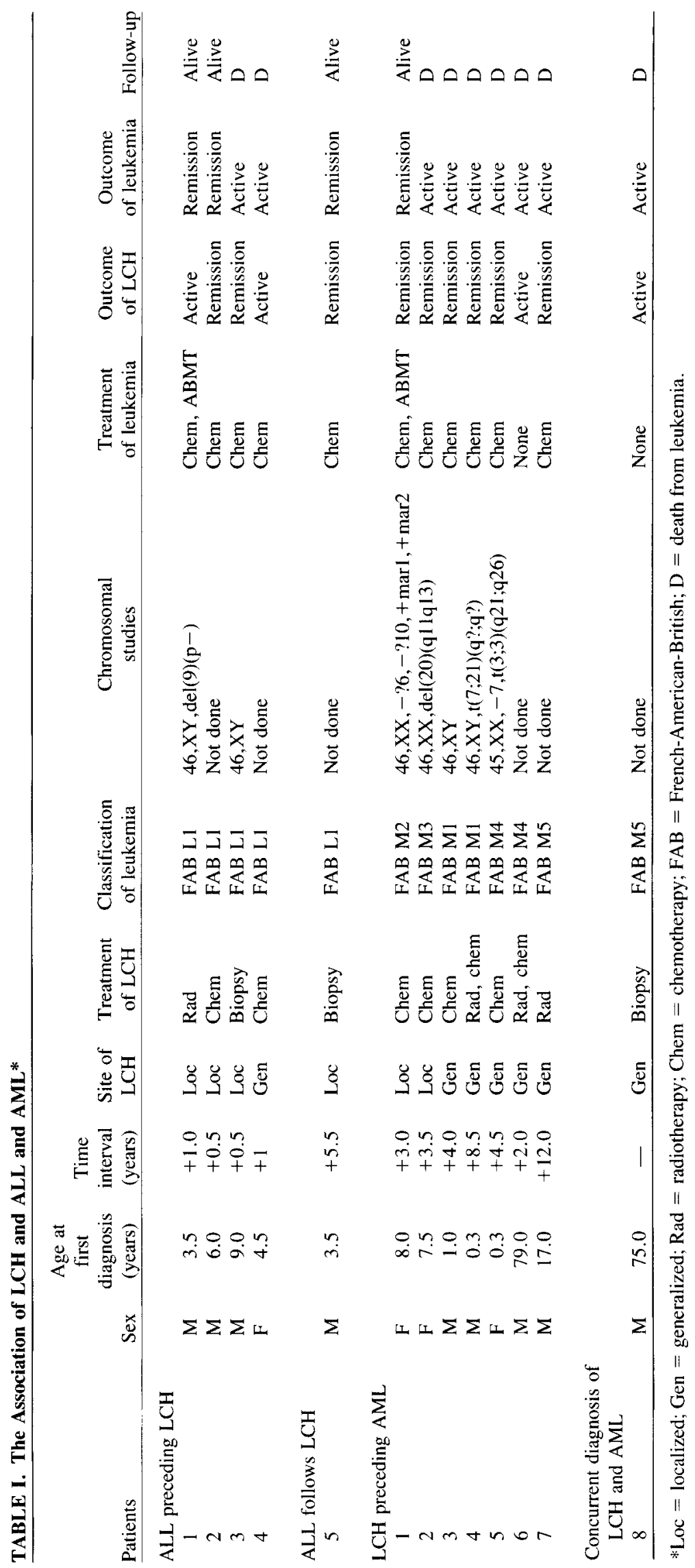


TABLE II. The Treatment in the Seven Patients With LCH in Whom the Associated AML Developed After Initial Therapy

\begin{tabular}{|c|c|c|c|c|c|c|}
\hline \multirow[b]{2}{*}{ Patients } & \multicolumn{5}{|c|}{ Chemotherapy } & \multirow[b]{2}{*}{ Radiotherapy } \\
\hline & $\begin{array}{l}\text { Vinblastine/ } \\
\text { vincristine }\end{array}$ & Methotrexate & Cyclofosfamide & Chlorambucil & $\begin{array}{c}\text { VP-16/VM-26 } \\
\left(+ \text { total dose, } \mathrm{mg} / \mathrm{m}^{2}\right)\end{array}$ & \\
\hline 1. & & & & & $X(8,400)$ & \\
\hline 2. & $X$ & & & & $X(4,800)$ & \\
\hline 3. & $\mathrm{X}$ & $X$ & $\mathrm{X}$ & & $X(13,500)$ & \\
\hline 4. & $X$ & & $\mathrm{X}$ & $\mathrm{X}$ & $X(5,000)$ & $X$ \\
\hline 5. & $X$ & & & $\mathrm{X}$ & & \\
\hline 6. & $X$ & & & & & $X$ \\
\hline 7. & & & & & & $X$ \\
\hline
\end{tabular}

with a bone biopsy only. The ALL in this child occurred over 5 years later and may have been a chance occurrence.

Conversely, in eight cases in which there was the association of LCH and AML the diagnosis of $\mathrm{LCH}$ preceded that of AML in all but one, and in all of these instances the LCH was treated with chemotherapy alone (four cases), radiation alone (one case), or both modalities (two cases). In these seven cases the temporal sequence and the interval between the initial therapeutic exposure and the development of AML are most consistent with a therapy-related leukemia. Alternately, it could be speculated that the initial diagnosis of LCH was incorrect, however, this seems unlikely since the cases that lacked a definitive diagnosis were specifically reviewed by their local pathologist to eliminate such a possibility. The morphologic characteristics of the AML were heterogenous. Three of the four cases showed cytogenetic abnormalities which are known to exist by secondary leukemia. None showed the 11q23 translocation characteristic of the epipodophyllotoxin-associated AML. An analogous situation appears to exist for the broader category of LCH and malignancy.

In our previous review of 91 reported cases of $\mathrm{LCH}$ and malignancy [1], 39 had LCH with malignant lymphomas and in 12 the LCH was associated with lung carcinomas. The intimate and simultaneous association of $\mathrm{LCH}$ with malignant lymphoma and lung carcinomas suggested strongly that the process that led to this specific association was a reactive one. In the remaining 18 cases of LCH in association with a variety of other solid tumors, the LCH preceded the solid tumor 16 times, with $69 \%(11 / 16)$ of the malignant diseases developing in the radiation field used for the treatment of the $\mathrm{LCH}$. Similarly, in the 22 cases in which LCH was reported in association with leukemia, $16(73 \%)$ were AML. In 64\% (14 cases) the diagnosis of $\mathrm{LCH}$ preceded the diagnosis of leukemia, and it was concluded that because of the latency of the leukemia following the diagnosis of $\mathrm{LCH}$, it was suggestive of a therapy-related process.

LCH may present a variety of clinical situations, ranging from a solitary lesion of bone to a multisystem, life- threatening disorder. The clinical course of localized disease of bone is generally benign, tends not to recur locally, and is not influenced greatly by any form of treatment. Because of the progressive nature of generalized LCH, many patients have been treated with systemic chemotherapeutic agents. Beneficial results have been reported with several chemotherapeutic agents, including corticosteroids, vincristine, vinblastine, methotrexate, cyclophosphamide, chlorambucil, nitrogen mustard, cytosine-arabinoside, 6-mercaptopurine, daunorubicin, and etoposide [3]. Several studies have reported the use of combination chemotherapy. Although the development of chemotherapy has improved survival considerably in children with cancer, this is not as dramatic for generalized LCH.

The LCH-AML cases reported here and previously raise concern about the induction of leukemia by $\mathrm{LCH}$ therapy. There have been extensive reports of survivors of pediatric malignancies who developed secondary AML after successful treatment with alkylating agents [4,5], epipodophyllotoxin [6,7], and radiotherapy [8]. Epipodophyllotoxins, however, have been shown to be very effective in disseminated $\mathrm{LCH}[9,10]$. The risk of secondary AML for this drug appears to be related to the total dose and the schedule of administration [6,7]. Furthermore, in most if not all reports, VP-16/VM-26 is given in combination with other chemotherapeutics. In the cases who were enrolled in the registry, just one was treated with VP-16 as single agent and in most cases the treatment was given for a very long time with a high total dose.

It is imperative however to remember that patients with disseminated $\mathrm{LCH}$, especially those with organ dysfunction at the time of diagnosis, are expected to have only a 45-50\% probability of surviving for 5 years [11]. Although complications for some of the more hazardous types of therapies are well known, the most effective and safe treatment for LCH has not yet been established. Only cooperative large scale clinical studies will be able to provide insight into the role of chemotherapy in this disorder and the risk/benefit ratio associated with therapy. Continuing registration of $\mathrm{LCH}$ patients with malignant 
disease with the Langerhans Cell Histiocytosis-Malignancy Study Group of the Histiocyte Society will also help define that ratio.

\section{ACKNOWLEDGMENTS}

The cooperation of the Histiocyte Society and its members is gratefully acknowledged.

\section{REFERENCES}

1. Egeler RM, Neglia J, Puccetti DM, Brennan C, Nesbit ME: The association of Langerhans cell histiocytosis with malignant neoplasms. Cancer 71:865-873, 1993.

2. Writing Group of the Histocyte Society: Histiocytosis syndromes in children. Lancet I:208-209, 1987.

3. Egeler RM, Nesbit ME Jr: Current concepts and treatment in Langerhans cell histiocytosis. In Voûte PA, Barrett A, Lemerle J (eds): "Cancer in Children, Clinical Management," 3rd ed. Heidelberg: Springer-Verlag, 1992, pp. 158-168.

4. Michels SD, McKenna RW, Arthur DC, Brunning RD: Therapyrelated acute myeloid leukemia and myelodysplastic syndrome: A clinical and morphologic study of 65 cases. Blood 65:1364-1372, 1985.

5. Rubin CM, Arthur DC, Woods WG, Lange BJ, Nowell PC,
Rowley JD, Nachman J, Bostrom B, Baum ES, Suarez CR, Shah NR, Morgan E, Maurer HS, McKenzie SE, Larson RA, Le Beau MM: Therapy related myelodysplastic syndrome and acute myeloid leukemia in children: Correlation between chromosomal abnormalities and prior therapy. Blood 78:2982-2988, 1991.

6. Pui CH, Behm FG, Raimondi SC, Dodge RK, George SL, Rivera GK, Mirro J, Kalwinsky DK, Dahl GV, Murphy SB, Crist WM, Williams DL: Secondary acute myeloid leukemia in children treated for acute lymphoid leukemia. N Engl J Med 321:136-142, 1989.

7. Pui CH, Ribeiro RC, Hancock ML, Rivera GK, Evans WE, Raimondi SC, Head DR, Behm FG, Mahmoud MH, Sandlund JT, Crist WM: Acute myeloid leukemia in children treated with epipodophyllotoxins for acute lymphoblastic leukemia. N Engl J Med 325:1682-1687, 1991.

8. Newton WA, Meadows AT, Shiamada H, Bunin GR, Vawter GF: Bone sarcomas as malignant neoplasms following childhood cancer. Cancer 67:193-201, 1991.

9. Ceci A, De Terlizzi M, Collela R, Balducci D, Grazia Toma M, Grazia Zurlo M, Macchia P, Mancini A, Indolfi P, Locurto $M$, Calculli G, Cristiani M, Castello M: Etoposide in recurrent childhood Langerhans' cell histiocytosis: An Italian cooperative study. Cancer 62:2528-2531, 1988.

10. Broadbent V, Pritchard J, Yeomans E: Etoposide (VP16) in the treatment of multisystem Langerhans cell histiocytosis (Histiocytosis X). Med Pediatr Oncol 17:97-100, 1989.

11. Komp DM: Langerhans cell histiocytosis [Editorial]. N Engl J Med 316:747-748, 1987. 